Article

\title{
Experimental Parameter Tuning of a Portable Water Generator System Based on a Thermoelectric Cooler
}

\author{
Ingrid Casallas (D, Manuel Pérez (D), Arturo Fajardo *(D) and Carlos-Ivan Paez-Rueda (D) \\ Department of Electronic Engineering, Pontificia Universidad Javeriana, Bogotá 110311, Colombia; \\ ingrid.casallas@javeriana.edu.co (I.C.); manuel.perez@javeriana.edu.co (M.P.); \\ paez.carlos@javeriana.edu.co (C.-I.P.-R.) \\ * Correspondence: fajardoa@javeriana.edu.co
}

Citation: Casallas, I.; Pérez, M.;

Fajardo, A.; Paez-Rueda, C.-I.

Experimental Parameter Tuning of a Portable Water Generator System Based on a Thermoelectric Cooler Electronics 2021, 10, 141.

https://doi.org/10.3390/

electronics10020141

Received: 30 November 2020

Accepted: 6 January 2021

Published: 11 January 2021

Publisher's Note: MDPI stays neutral with regard to jurisdictional clai$\mathrm{ms}$ in published maps and institutional affiliations.

Copyright: (C) 2021 by the authors. Licensee MDPI, Basel, Switzerland. This article is an open access article distributed under the terms and conditions of the Creative Commons Attribution (CC BY) license (https:// creativecommons.org/licenses/by/ $4.0 /)$.

\begin{abstract}
Atmospheric Water Generators (AWG) are a promising technology solution to the water scarcity in the world. However, their main drawback is the high power consumption. This paper presents the experimental optimization process of a Portable Atmospheric Water Generator (PAWG) prototype based on a thermometric cooler. This process was developed by an exhaustive search of the experimental solution space, which was generated by parametric sweeps of two parameters (i.e., control voltages in the PAWG), which are related to the power consumption of the PAWG and the physical variables involved in the water condensation process (i.e., the airflow and the temperature on the water condenser element). As a result, we found the existence of two optimal operation points under a constant value of relative humidity; one of them maximizes the amount of water generated, and the other one maximizes the system performance (i.e., the ratio between the generated water and consumed power in $\mathrm{mL} / \mathrm{Wh}$ ). The resulting Figures of Merit (FoMs) of the PAWG prototype were $0.33 \mathrm{~mL} / \mathrm{h}$ of generated water and $0.22 \mathrm{~mL} / \mathrm{Wh}$ for the system performance.
\end{abstract}

Keywords: atmospheric water generator; vapor water condensation; parameter tuning; Peltier effect

\section{Introduction}

An AWG generates liquid water from the ambient air humidity [1]. This device is a water harvester, which condenses the water vapor by cooling the air below its dew point [1] The dew point is the temperature at which the air water vapor reaches saturation and it is condensed into dew [2]. Under constant atmospheric pressure, the dew point depends only on the Relative Humidity $(R H)$ and the ambient temperature $\left(T_{a m b}\right)$ [3]. The conventional AWG systems have been studied as a strategy to face water scarcity problems without power or size constraints for agricultural or domestic purposes [1,4-8]. A Portable Atmospheric Water Generator (PAWG) is an AWG device characterized by a smaller size, lighter weight, and lower power consumption than a conventional AWG [9]. The PAWG would be useful for cyclists, hikers, or expeditionaries because they can transport their water source [10]. Therefore, a PAWG must be designed under energy and size constraints for people who perform activities in outdoor environments [10]. Furthermore, a self-sustaining PAWG based on water and solar harvesters has been explored to increase the device and user autonomy of energy and water sources, respectively [11].

The AWG devices could be based on the vapor compression cycle, a Thermoelectric Cooler (TEC), or adsorption/absorption refrigeration [1]. However, the PAWGs reported in the analyzed literature are based on TEC devices. In an AWG system based on a TEC, the dew point is reached by cooling the air using the thermoelectric cooling effect (or Peltier effect) [12]. The general structure of a PAWG is shown in Figure 1. In a PAWG device, the TEC transforms electric energy into a temperature difference by the thermoelectric cooling effect, which consists of heat transfer from the cool side to the hot one [13]. This heat transfer could be optimized by the use of heat sinks on both sides of the cooler [14]. In this paper, the inside heat sink will be referred to as the water condenser element because 
the water vapor condensation takes place in this heat sink, and the system composed of the TEC and its heat sinks will be referred to as the extended TEC. Furthermore, the airflow (inside or outside) could be produced by natural or forced convection. Typically in forced convection, the airflow is forced in both the outside and inside of the AWG. Moreover, the outside and inside airflow is produced by an active heat sink and a semi-closed cooling cabin with inlet and/or outlet fans, respectively.

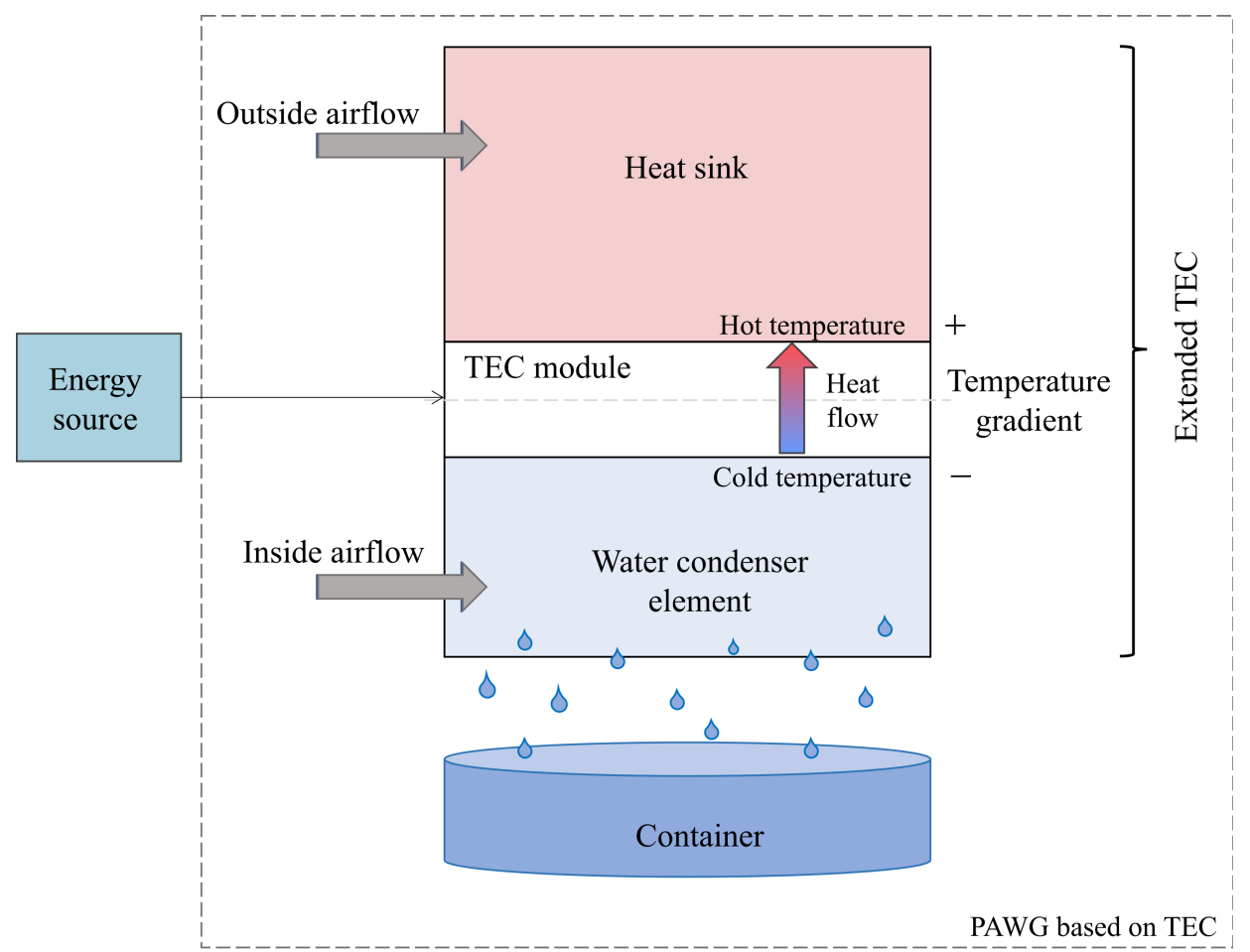

Figure 1. Structure of an Portable Atmospheric Water Generator (PAWG) prototype based on Thermoelectric Cooler (TEC).

Several PAWG prototypes with embedded TECs have been developed in the literature [9-12,14]. In [9,10], the authors designed a portable AWG with two TEC modules. The system experimentally investigated the effect of the inlet airflow rate and $R H$. The results showed that the amount of water increased with the rising $R H$ and inlet airflow rate. In [11], a PWAG with two TECs to sustain young plants in drier periods was presented. The authors evaluated an autonomous solar photovoltaic system and a control algorithm to optimize energy consumption versus generated water under different environmental conditions. They found that the specific power density of the PAWG must be increased to increase the volume of water condensed. Furthermore, they found that this trend presents a saturation phenomenon when the $R H$ is too low. In [12], the authors developed a PAWG with ten Peltier modules. This research found a direct correlation between the water generated and the surface area of the water condensation element. In their prototype, an increase in the area of the water condenser element of $1150 \%$ increased the generated water by $81 \%$. In [14], the authors designed a PAWG using four TECs. They analyzed the effect of the TEC current and the use of an intake fan in the water generation. The results showed that the increase of the voltage difference across the TECs increased the water generation rates but increased the energy consumption. Additionally, in [15], a PAWG model based on an electric analogy was proposed, which was validated experimentally. Their prototype was optimized by parameter tuning under experimental conditions. The analyzed parameters were the supply voltages of the TEC and inlet fan. Moreover, in [16], a computer-aided design approach based on computational fluid dynamics was presented. The authors optimized the cooling cabin considering physical parameters such as temperature, $R H$, airflow magnitude, pressure, the form of 
airflow, and water productivity. Finally, in [17], a low-power and low-cost PAWG was proposed; the system is shown in Figure 2. The authors developed a low-cost control device, which could control the main parameters of the PAWG prototype (i.e., the supply voltages of the TEC, active heat sink, and inlet fan). This approach allows optimizing the PAWG prototype by dynamic parametric tuning. Considering the presented State-of-theArt (SoA), the main factors involved in the design and optimization of PAWG based on TECs are summarized in Figure 3. Furthermore, the main drawback of published PAWGs based on TEC technologies is their high energy consumption. Moreover, the main involved variables are well identified. However, their interaction is not well known. Besides, the optimization of the PAWG parameters in the design phase and the prototype phase has been little explored, especially for low-power devices.

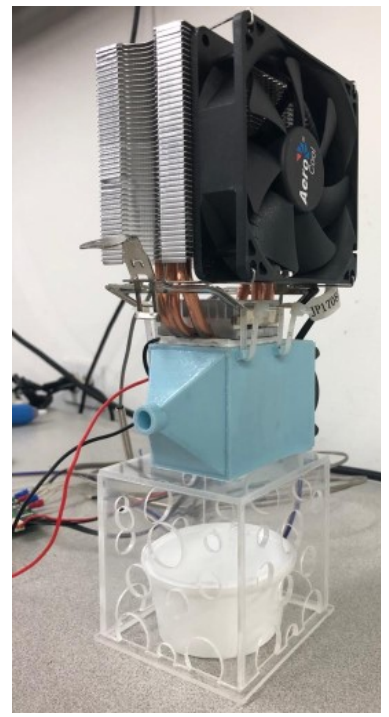

(a)

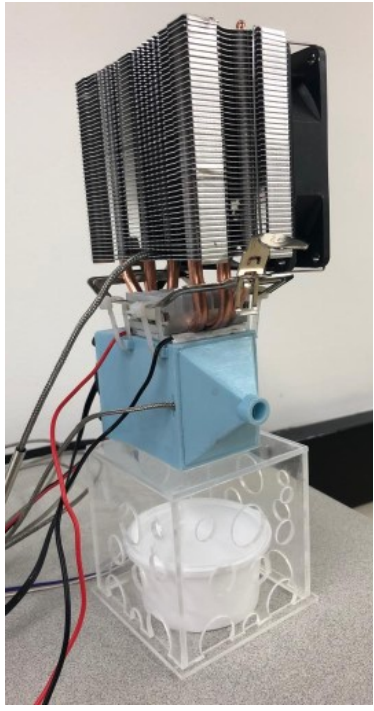

(b)

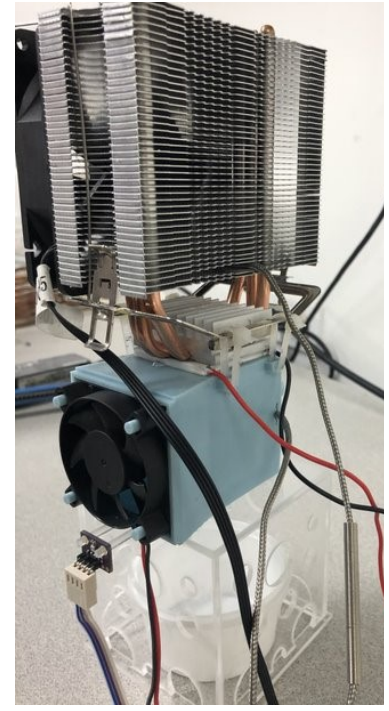

(c)

Figure 2. PAWG prototype [17]. (a) right side view; (b) left side view; (c) rear view.

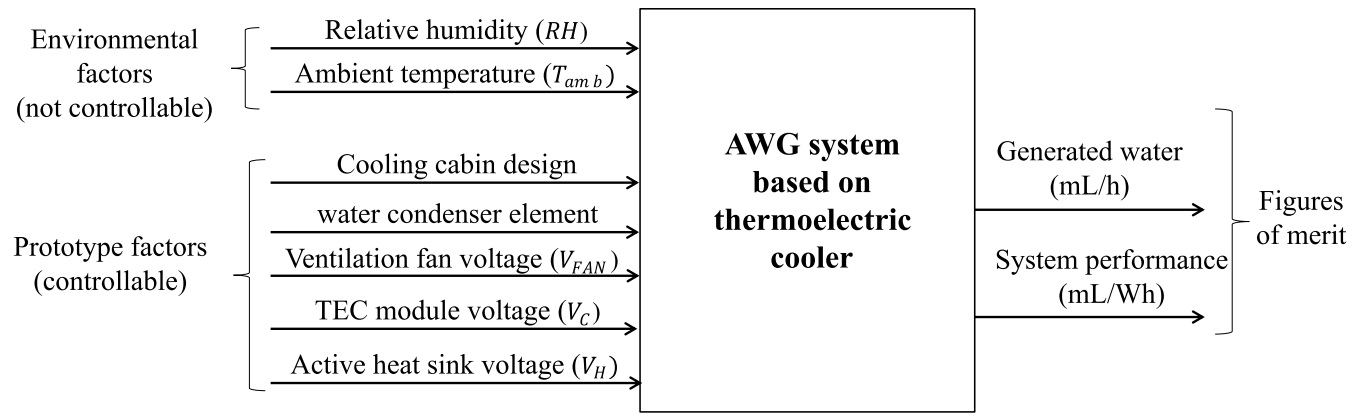

Figure 3. Factors affecting water generation in an Atmospheric Water Generator (AWG) system based on a thermoelectric cooler.

In this paper, the experimental parameter tuning of a PAWG prototype developed in [17] is presented. In this process, the temperature and airflow on the cooling cabin are tuned to maximize the generated water and the system performance (i.e., the ratio between the generated water and consumed power in $\mathrm{mL} / \mathrm{Wh}$ ). The results show the existence of the optimum value of the tuned parameters (i.e., the supply voltage of the TEC and the inlet fan) under a constant value of the $R H$. The outline of the paper is as follows. The AWG prototype is shown in Section 2. The parameter tuning process is described in Section 3. The results and their analysis are presented in Section 4 . Finally, the conclusions are given in Section 6. 


\section{AWG Prototype}

The AWG prototype analyzed in this paper consists of an extended TEC and a cooling cabin with an inlet fan. The thermoelectric cooler is the TEC1-12706, which uses bismuth telluride $\left(\mathrm{Bi}_{2} \mathrm{Te}_{3}\right)$ as the thermoelectric material, having $127 \mathrm{P}-\mathrm{N}$ couples, a maximum voltage $($ Vmax $)$ of $14.4 \mathrm{~V}$, and a maximum current (Imax) of $6.4 \mathrm{~A}$. The active heat sink is a Central Processing Unit (CPU) air cooler with dimensions of $12.0 \mathrm{~cm} \times 8.1 \mathrm{~cm} \times 12.25 \mathrm{~cm}$, which uses heat core touch technology with three ultra-efficient thermal heat pipes, a thermal design power up to $120 \mathrm{~W}$, and a Pulse-Width Modulation (PWM) high-pressure fan. This element is placed on the hot zone of the thermoelectric cooler to provide heat dissipation and allows temperatures on the cold zone below the dew point.

In the cooling cabin, the water condenser element is placed, and the ventilation system is located in a physical assembly. The water condenser element is a specific device, whose geometric structure was developed to facilitate the water condensation process in the AWG prototype [17]. It is composed of five aluminum sheets with vertical slots, which are placed on an aluminum square base with horizontal grooves by pressure coupling, as shown in Figure 4. The ventilation system consists of a $5.0 \mathrm{~cm} \times 1.1 \mathrm{~cm} \times 5.0 \mathrm{~cm}$ DC fan with a nominal power of $1.2 \mathrm{~W}(0.1 \mathrm{~A}$ at $12 \mathrm{~V})$, which provides constant airflow to the water condenser element. The physical assembly is a $10.65 \mathrm{~cm} \times 6.70 \mathrm{~cm} \times 7.05 \mathrm{~cm}$ structure that has a cooling space to place the water condenser element, an airflow inlet that physically supports the ventilation system fan, and an air outlet hole. Furthermore, this part collects the condensed water through the water outlet hole and provides physical stability to the prototype, as shown in Figure 5. The AWG final prototype is shown in Figure 6. It groups the heat sink, the thermoelectric cooler, and the cooling cabin with plastic ties placed on the heat sink and heat sink brackets. Moreover, this prototype includes a cubic base and a container for collecting water.

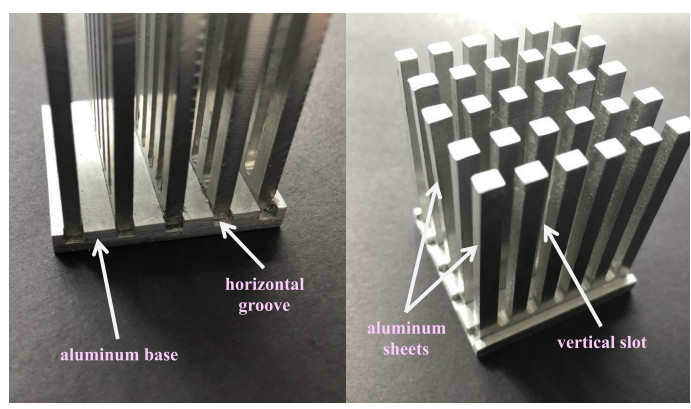

(a)

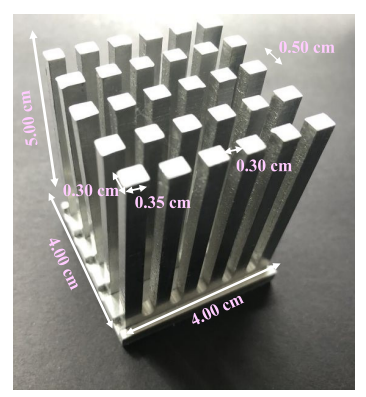

(b)

Figure 4. Water condenser element. (a) Parts. (b) Dimensions.

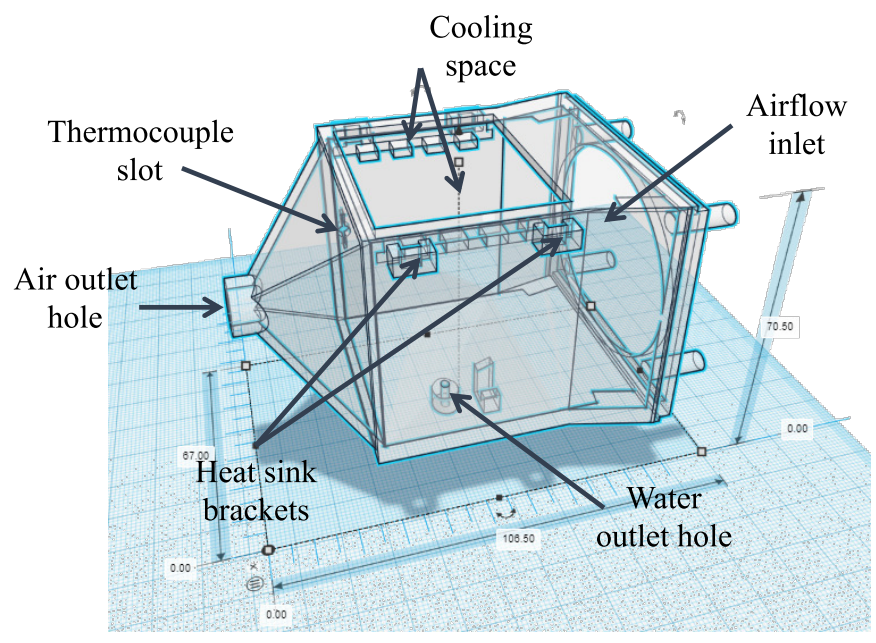

Figure 5. Physical assembly of the cooling cabin. 


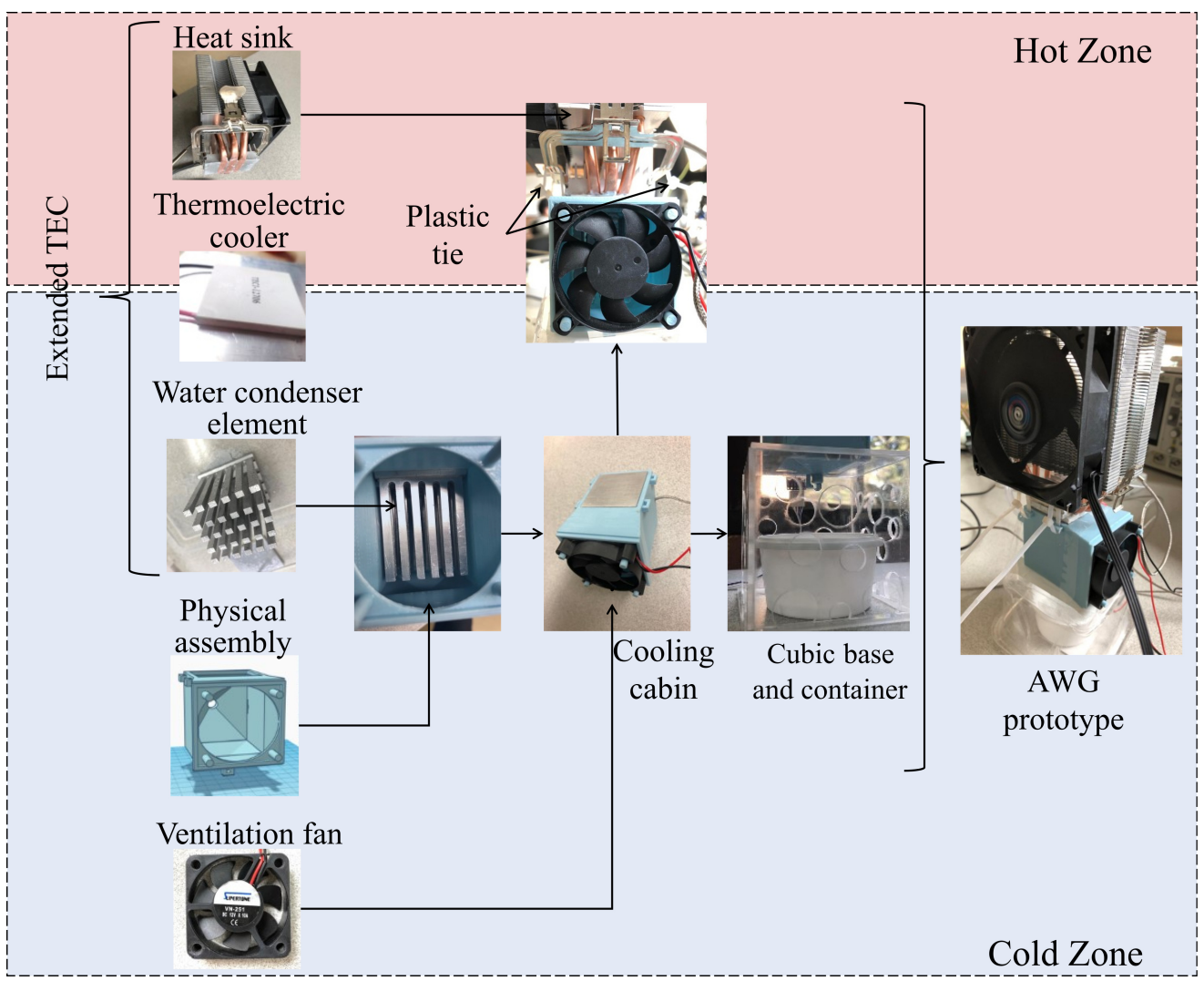

Figure 6. Parts of the AWG prototype [17].

\section{Description and Results of the Parameter Tuning Process}

The amount of water generated by an AWG prototype depends on multiple factors, as shown in Figure 3. On the one hand, the $R H$ and $T_{a m b}$ are uncontrolled environmental variables. On the other hand, the cooling cabin and water condenser element dimensions are design variables, which could be optimized only in the design phase of the AWG system. Therefore, the supply voltages of the TEC, the inlet fan, and the active heat sink (i.e., $V_{C}$, $V_{F A N}$, and $V_{H}$ ) are the only system parameters that can be optimized in the proposed AWG prototype. The tests were performed with a fixed value of $V_{H}$ (i.e., $12 \mathrm{~V}$ ) and under quasi-fixed environmental conditions. Therefore, $V_{C}$ establishes the condenser element temperature $\left(T_{\text {cold }}\right)$, and $V_{F A N}$ determines the cooling cabin airflow $\left(A_{C C}\right)$. The Figure of Merit ( $\mathrm{FoM}$ ) is the quantity used to characterize the performance of a device related to its alternatives. The performance of the PAWG proposed in [17] was analyzed through the FoM defined as:

$$
P_{s y s}=\frac{w_{g / h}}{P_{A W G}}\left[\frac{\mathrm{mL} / \mathrm{h}}{\mathrm{W}}\right]
$$

where $w_{g / h}$ is the generated water rate in $\mathrm{mL} / \mathrm{h}$ and $P_{A W G}$ is the power consumed by the PAWG in $\mathrm{W}$, which are given by:

$$
\begin{gathered}
w_{g / h}=\frac{w_{A W G}}{\mathrm{t}} \\
P_{A W G}=P_{H}+P_{F A N}+P_{C}
\end{gathered}
$$

where $w_{A W G}$ is the generated water during the test, $t$ is the test time, $P_{H}$ is the power consumed by the active heat sink, $P_{F A N}$ is the power consumed by the inlet fan, and $P_{C}$ is the power consumed by TEC module.

However, in the analyzed literature, only one FoM is not well established. Furthermore, sometimes, $w_{g / h}$ or $P_{A W G}$ are reported as the main FoMs. Using $P_{s y s}$ and $w_{g / h}$ as the tuning goals, the values of the system variables were examined in sixteen tests. The developed process consists of an experimental evaluation of the goals under parametric sweeps 
of the voltage variables. In this process, $V_{C}$ and $V_{F A N}$ were swept, and their optimum values were found. The $V_{C}$ parametric sweep was made from $2 \mathrm{~V}$ to $14 \mathrm{~V}$, with steps of $4 \mathrm{~V}$, and the parametric sweep was made from $3 \mathrm{~V}$ to $12 \mathrm{~V}$, with steps of $3 \mathrm{~V}$. The proposed test grid is shown in Figure 7.

\begin{tabular}{|c|c|c|c|c|}
\hline $14 \mathrm{~V}$ & Test 1 & Test 2 & Test 3 & Test 4 \\
\hline $10 \mathrm{~V}$ & Test 5 & Test 6 & Test 7 & Test 8 \\
\hline $6 \mathrm{~V}$ & Test 9 & Test 10 & Test 11 & Test 12 \\
\hline $2 \mathrm{~V}$ & Test 13 & Test 14 & Test 15 & Test 16 \\
\hline & $3 \mathrm{~V}$ & $6 \mathrm{~V}$ & $9 \mathrm{~V}$ & $12 \mathrm{~V}$ \\
\hline
\end{tabular}

Figure 7. Test grid of the exhaustive search.

The $V_{C}$ voltage is related to the specific power density of the extended TEC $\left(S P D_{E C}\right)$, which is given by:

$$
S P D_{E C}=\frac{P_{E C}}{V_{E C}}
$$

where $V_{E C}$ and $P_{E C}$ are the volume and consumed power of the extended TEC, respectively. In the prototype, the $V_{E C}$ value is $0.1319 \mathrm{~m}^{3}\left(0.0118 \mathrm{~m}^{3}, 0.048 \mathrm{~m}^{3}\right.$, and $0.072 \mathrm{~m}^{3}$ are the volumes of the active heat sink, TEC, and water condenser element, respectively). $P_{E C}$ is calculated as:

$$
P_{E C}=P_{H}+P_{C}
$$

where $P_{H}$ is the power consumed by the active heat sink and $P_{C}$ is the power consumed by the thermoelectric cooler. $P_{H}$ has a fixed power value of $2.4 \pm 0.0648 \mathrm{~W}$ (i.e., $12 \pm 0.0050 \mathrm{~V}$ $@ 0.2 \pm 0.0054 \mathrm{~A}$ ), and $P_{C}$ is calculated as $P_{C}=V_{C} I_{C}$ from the measured voltage and current values of the TEC module operating in the PAWG device (i.e., $V_{C}$ and $I_{C}$, respectively). The empirical data and the calculated values of $P_{C}$ are plotted in Figure 8. Finally, $S P D_{E C}$ is calculated based on $P_{E C}$ and $V_{E C}$, and the results are summarized in Table 1.

To quantify this relationship between $V_{F A N}$ and $A_{C C}$, an empirical characterization of the system is required. However, assuming a constant torque of the inlet fan, the maximum $A_{C C}$ value could be estimated as:

$$
A_{C C_{\max }}=A_{n} \frac{V_{F A N}}{V_{F A N_{n}}}
$$

where $A_{n}$ and $V_{F A N_{n}}$ are the nominal airflow and voltage of the inlet fan, respectively. We searched the datasheet of our low-cost inlet fan (i.e., Supertone VN-251, 12V @ 0.1 A, with seven blades and $50 \mathrm{~mm} \times 50 \mathrm{~mm} \times 10 \mathrm{~mm}$ in size); however, it was not available at the time of this report. As a rough approximation, $A_{C C_{\max }}$ is calculated based on the datasheet of the DC0501012H2B [18], which has the same size, electrical specification, and geometrical variables (i.e., the number and shape of blades) as our fan. The estimated values of $A_{C C_{\max }}$ are summarized in Table 1. 


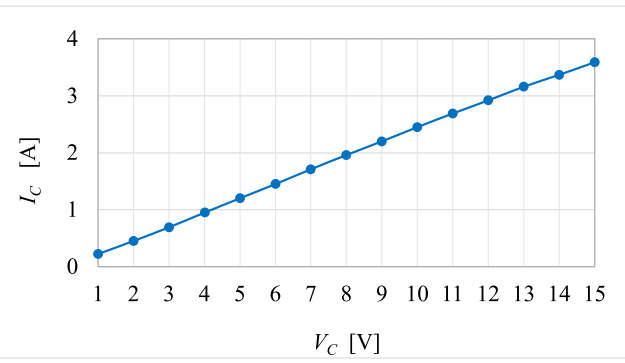

(a)

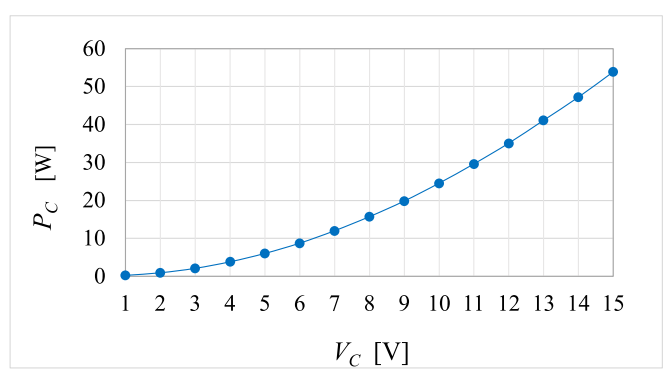

(b)

Figure 8. Experimental data of the thermoelectric cooler TEC1-12706 operating in the PAWG. (a) Current vs. voltage plot; (b) Power vs. voltage plot.

Table 1. Calculated value of $S P D_{E C}$ and estimated value of $A_{C C_{\max }}$.

\begin{tabular}{ccccccc}
\hline Physical Variable & Test-Grid Axes & Type & \multicolumn{3}{c}{ Test-Grid Scale Relationship } \\
\hline$V_{C}(\mathrm{~V})$ & X-axis & Experimental & 2.0 & 6.0 & 10.0 & 14.0 \\
$S P D_{E C}\left(\mathrm{~W} / \mathrm{m}^{3}\right)$ & X-axis & Calculated & 25.0 & 84.2 & 203.9 & 375.9 \\
$V_{F A N}(\mathrm{~V})$ & Y-axis & Experimental & 3.0 & 6.0 & 9.0 & 12.0 \\
$A_{C C_{\max }}\left(\mathrm{ft}^{3} / \mathrm{min}\right)$ & Y-axis & Estimated & 3.2 & 6.4 & 9.5 & 12.7 \\
\hline
\end{tabular}

* Estimated using $A_{n}=12.7 \mathrm{ft}^{3} / \mathrm{min}$ and $V_{F A N_{n}}=12 \mathrm{~V}$.

At the beginning of each test, we measured with a digital multimeter (i.e., Fluke 45) the DC voltage and current of the inlet fan (i.e., $V_{F A N}$ and $I_{F A N}$ ), the DC voltage and current of the active heat sink (i.e., $V_{H}$ and $I_{H}$ ), and the DC voltage and current of the thermoelectric cooler (i.e., $V_{C}$ and $I_{C}$. The Fluke 45 has an accuracy as described in [19]. During the tests, the PAWG used an energy recovery system to improve its performance; this system harvest and conducts the cool airflow through a tube from the air outlet hole to the active heat sink to decrease its external temperature, as shown in Figure 9a. Furthermore, as is shown in Figure 9b,c, the PAWG was equipped with type-K thermocouples to measure the physical variables related to the extended TEC, which are the temperatures of the active heat sink $\left(T_{\text {hot }}\right)$ and the water condenser element $\left(T_{\text {cold }}\right)$. The thermocouple analog voltages were measured with the NI USB-621 data acquisition module. The uncertainty of this measurement is $\Delta \mathrm{T}= \pm 4.35^{\circ} \mathrm{C}$, which is given by the sum of the thermocouple accuracy (i.e., $\pm 2.2^{\circ} \mathrm{C}$ or $\pm 0.75 \%$ [20]) and the acquisition module accuracy (i.e., $\pm 2.15^{\circ} \mathrm{C}$ ) [21]. The acquisition module accuracy is given by:

$$
\Delta T=\frac{88 \mu \mathrm{V}}{41 \mu \mathrm{V} /{ }^{\circ} \mathrm{C}}=2.15^{\circ} \mathrm{C}
$$

where $88 \mu \mathrm{V}$ is the full-scale accuracy of the USB-621 device (considering a scale between $-0.2 \mathrm{~V}$ and $0.2 \mathrm{~V} \mathrm{[22])} \mathrm{and} 41 \mu \mathrm{V} /{ }^{\circ} \mathrm{C}$ is the thermocouple sensitivity of a standard type-K thermocouple at room temperature [23]. In these measures, the data were acquired on a computer using SignalExpress ${ }^{\mathrm{TM}}$ software with a period rate of a second during the test time (i.e., an hour). It is important to note that the cooling cabin was designed to allow the pass of the thermocouple of the water condenser element through the thermocouple slot shown in Figure 5. 
Moreover, and during the test, the environmental conditions ( $R H$ and $\left.T_{a m b}\right)$ were measured with the BME280 sensor, which was placed $12 \mathrm{~cm}$ from the PAWG device, as shown in Figure 9d. This sensor transmits one data measurement each second by a serial communication protocol (i.e., $\mathrm{I}^{2} \mathrm{C}$ ) to an Arduino Mega 2560 board, which displays the data in the serial monitor of the Arduino integrated development environment. The resulting data have an error of $\Delta R H= \pm 3 \%$ and $\Delta T_{a m b}= \pm 1{ }^{\circ} \mathrm{C}$ under nominal operation [24]. Finally, at the end of each test, the amount of water generated by the PAWG $\left(w_{A W G}\right)$ was measured using a syringe of $5 \mathrm{~mL}$ with an accuracy of $\pm 0.1 \mathrm{~mL}$. It is important to note that during Tests 1, 2, 5, 6, and 9, frost was generated in the water condenser element, as shown in Figure 10. In these cases, the amount of generated water was measured after the frost had thawed. Each test was developed for an hour, which was measured by an alarm set in a standard computer clock, and we estimated an error of one minute produced by the time gap between the alarm clock alert and the full disconnection of the system by the researcher.

The overall system measurements with their uncertainties are summarized in Table 2. It is important to note that even though the tests were performed in a laboratory room without any control of the environmental variables, these variables were very similar to each other. Furthermore, they were characterized by a low Standard deviation (Std. dev.) over the mean (i.e., a mean $T_{a m b}$ of $19.71^{\circ} \mathrm{C}$ and a mean $R H$ of $60.40 \%$, with an Std. dev. of $0.64{ }^{\circ} \mathrm{C}$ and $2.57 \%$, respectively). Finally, the PAWG FoMs were calculated based on the measured data and Equations (1) and (2). Furthermore, their uncertainties were calculated through the error propagation, and they are given by:

$$
\begin{gathered}
\Delta P_{(H, C, F A N)}=\left|P_{(H, C, F A N)}\right|\left(\sqrt{\left(\frac{\Delta V_{(H, C, F A N)}}{V_{(H, C, F A N)}}\right)^{2}+\left(\frac{\Delta I_{(H, C, F A N)}}{I_{(H, C, F A N)}}\right)^{2}}\right) \\
\Delta P_{A W G}=\sqrt{\left(\Delta P_{H}\right)^{2}+\left(\Delta P_{F A N}\right)^{2}+\left(\Delta P_{C}\right)^{2}} \\
\Delta w_{g / h}=\left|w_{g / h}\right|\left(\sqrt{\left(\frac{\Delta w_{A W G}}{w_{A W G}}\right)^{2}+\left(\frac{\Delta t}{t}\right)^{2}}\right) \\
\Delta P_{\text {sys }}=\left|P_{\text {sys }}\right|\left(\sqrt{\left(\frac{\Delta w_{g / h}}{w_{g / h} / h}\right)^{2}+\left(\frac{\Delta P_{A W G}}{P_{A W G}}\right)^{2}}\right)
\end{gathered}
$$

where $\Delta_{X}$ is the uncertainty of the variable $X$. The resulting FoMs and their uncertainties are summarized in Table 3. 


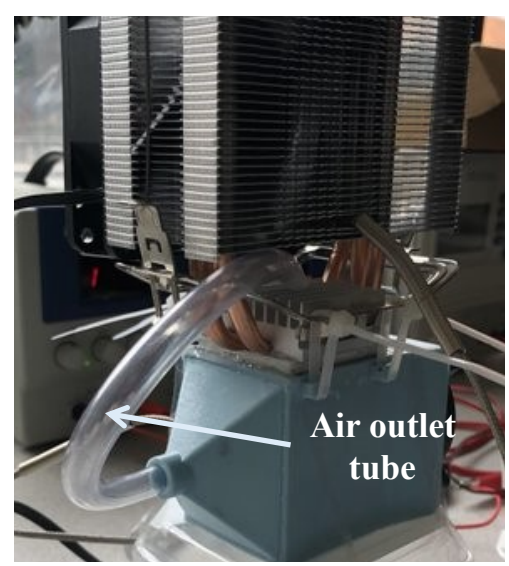

(a)

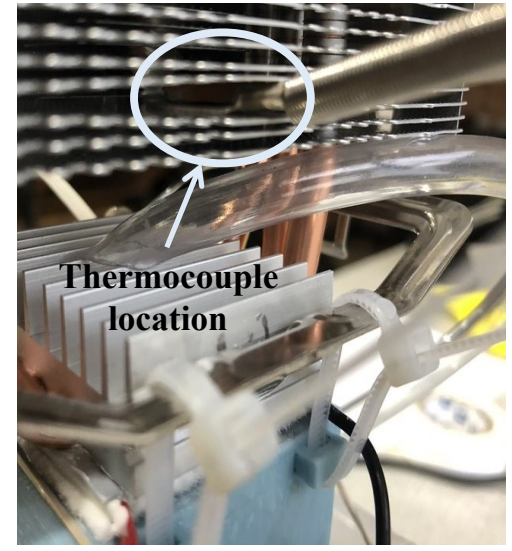

(b)

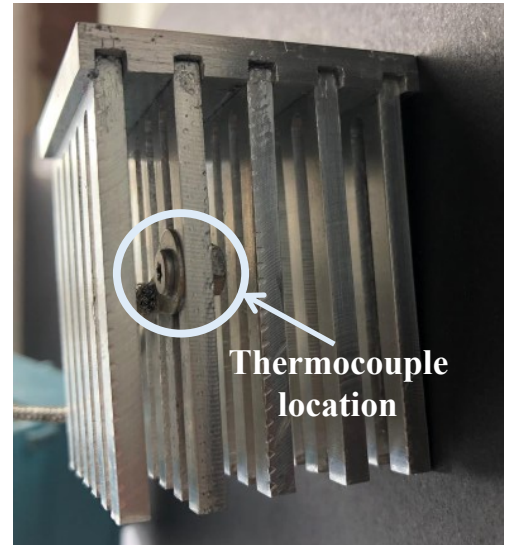

(c)

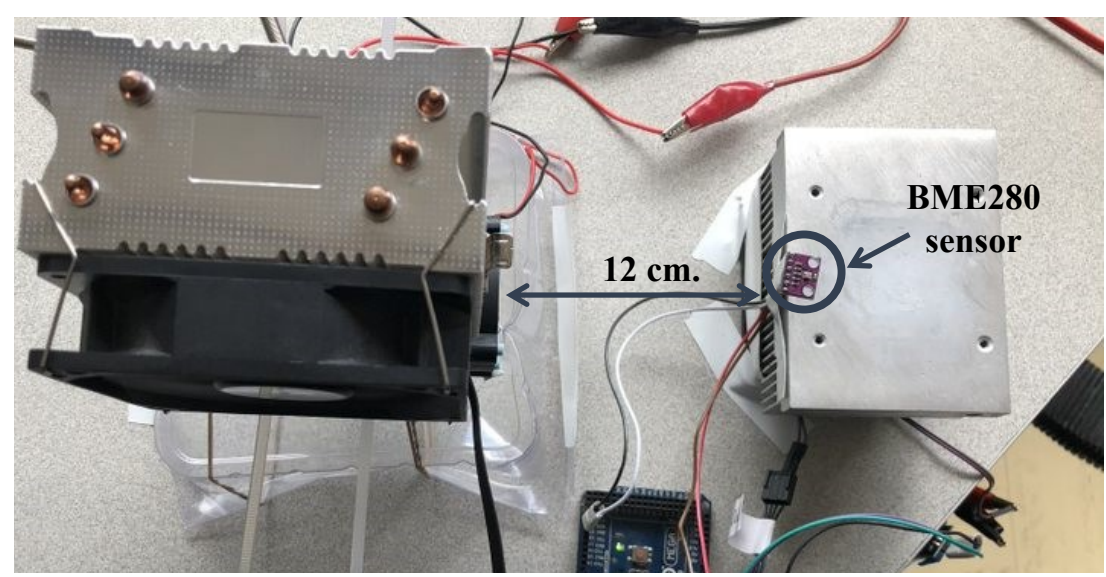

(d)

Figure 9. Test conditions (a) air outlet tube used; (b) thermocouple heat sink location; (c) thermocouple location of the water condenser element; (d) BME280 sensor location.

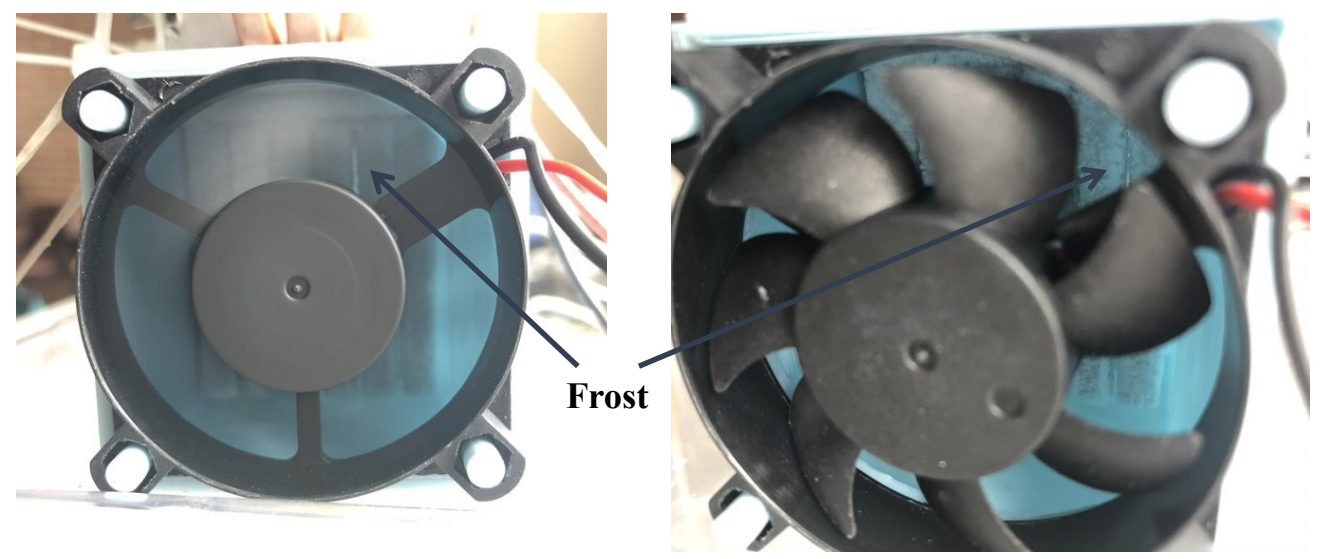

Figure 10. Generated frost on the water condenser element. 
Table 2. Measured variables' results for the parametric tuning.

\begin{tabular}{|c|c|c|c|c|c|c|c|c|c|c|}
\hline Tests Number & $V_{C}(\mathrm{~V})$ & $I_{C}(\mathrm{~A})$ & $V_{F A N}(\mathrm{~V})$ & $I_{F A N}(\mathrm{~A})$ & $\begin{array}{c}w_{A W G}{ }^{a} \\
(\mathrm{~mL})\end{array}$ & $t^{b}(\mathrm{~h})$ & $\begin{array}{c}\text { Average } T_{a m b} \\
{ }_{c}\left({ }^{\circ} \mathrm{C}\right)\end{array}$ & $\underset{(\%)}{\text { Average } R H^{d}}$ & $\begin{array}{c}\text { Average } T_{\text {hot }}{ }^{e} \\
\left({ }^{\circ} \mathrm{C}\right)\end{array}$ & $\begin{array}{c}\text { Average } T_{\text {cold }} \\
e\left({ }^{\circ} \mathrm{C}\right)\end{array}$ \\
\hline 1 & $14.00 \pm 0.0055$ & $3.62 \pm 0.0122$ & $3.01 \pm 0.0028$ & $0.03 \pm 0.00004$ & 0.4 & 1 & 20.11 & 56.90 & 25.76 & -10.88 \\
\hline 2 & $14.00 \pm 0.0055$ & $3.61 \pm 0.0122$ & $6.00 \pm 0.0035$ & $0.06 \pm 0.00005$ & 1.8 & 1 & 20.29 & 58.67 & 25.20 & -5.69 \\
\hline 4 & $14.00 \pm 0.0055$ & $3.60 \pm 0.0122$ & $12.00 \pm 0.0050$ & $0.09 \pm 0.00007$ & 3.3 & 1 & 18.79 & 62.65 & 24.93 & 5.52 \\
\hline 5 & $10.00 \pm 0.0045$ & $2.63 \pm 0.0103$ & $3.01 \pm 0.0028$ & $0.03 \pm 0.00004$ & 0.4 & 1 & 19.86 & 57.31 & 22.75 & -12.21 \\
\hline 6 & $10.00 \pm 0.0045$ & $2.62 \pm 0.0102$ & $6.00 \pm 0.0035$ & $0.06 \pm 0.00005$ & 1.9 & 1 & 20.04 & 61.19 & 22.98 & -6.31 \\
\hline 7 & $10.00 \pm 0.0045$ & $2.65 \pm 0.0103$ & $9.00 \pm 0.0043$ & $0.07 \pm 0.00006$ & 3.0 & 1 & 20.54 & 61.54 & 23.47 & -1.63 \\
\hline 9 & $6.00 \pm 0.0035$ & $1.53 \pm 0.0081$ & $3.01 \pm 0.0028$ & $0.03 \pm 0.00004$ & 0.4 & 1 & 19.59 & 56.94 & 21.64 & -5.53 \\
\hline 10 & $6.01 \pm 0.0035$ & $1.57 \pm 0.0081$ & $6.00 \pm 0.0035$ & $0.06 \pm 0.00005$ & 1.1 & 1 & 19.93 & 61.75 & 21.46 & -0.83 \\
\hline 11 & $6.00 \pm 0.0035$ & $1.58 \pm 0.0082$ & $9.00 \pm 0.0043$ & $0.07 \pm 0.00006$ & 2.7 & 1 & 20.64 & 62.14 & 21.55 & 2.77 \\
\hline 12 & $5.99 \pm 0.0035$ & $1.58 \pm 0.0082$ & $12.00 \pm 0.0050$ & $0.09 \pm 0.00007$ & 2.6 & 1 & 19.41 & 59.43 & 21.27 & 4.09 \\
\hline 13 & $2.00 \pm 0.0025$ & $0.47 \pm 0.0059$ & $2.99 \pm 0.0027$ & $0.03 \pm 0.00004$ & 0.1 & 1 & 19.47 & 56.34 & 19.50 & 12.40 \\
\hline 14 & $2.00 \pm 0.0025$ & $0.45 \pm 0.0059$ & $6.00 \pm 0.0035$ & $0.06 \pm 0.00005$ & 0.1 & 1 & 19.48 & 62.62 & 20.82 & 11.95 \\
\hline 15 & $2.00 \pm 0.0025$ & $0.47 \pm 0.0059$ & $9.00 \pm 0.0043$ & $0.07 \pm 0.00006$ & 0.1 & 1 & 20.16 & 64.54 & 20.50 & 12.54 \\
\hline 16 & $2.00 \pm 0.0025$ & $0.49 \pm 0.0060$ & $12.00 \pm 0.0050$ & $0.08 \pm 0.00006$ & 0.1 & 1 & 18.13 & 63.76 & 21.86 & 14.31 \\
\hline
\end{tabular}

${ }^{a}( \pm 0.1 \mathrm{~mL}),{ }^{b}( \pm 0.0167 \mathrm{~h}),{ }^{c}\left( \pm 1{ }^{\circ} \mathrm{C}\right),{ }^{d}( \pm 3 \%),{ }^{e}\left( \pm 4.35^{\circ} \mathrm{C}\right)$. 
Table 3. FoMs of the Portable Atmospheric Water Generator (PAWG) results under the parametric tuning.

\begin{tabular}{cccccc}
\hline Tests Number & $\boldsymbol{P}_{\boldsymbol{C}}(\mathbf{W})$ & $\boldsymbol{P}_{\boldsymbol{F A N}}(\mathbf{W})$ & $\boldsymbol{P}_{\text {AWG }} \boldsymbol{a}^{\mathbf{( W )}}$ & $\boldsymbol{w}_{\boldsymbol{g} / \boldsymbol{h}}(\mathbf{m L} / \mathbf{h})$ & $\boldsymbol{P}_{\text {sys }}(\mathbf{m L} / \mathbf{W h})$ \\
\hline 1 & $50.68 \pm 0.1725$ & $0.09 \pm 0.0001$ & $53.17 \pm 0.1843$ & $0.4 \pm 0.1002$ & $0.01 \pm 0.0019$ \\
2 & $50.54 \pm 0.1019$ & $0.36 \pm 0.0002$ & $53.30 \pm 0.1207$ & $1.8 \pm 0.1044$ & $0.03 \pm 0.0020$ \\
3 & $50.12 \pm 0.1010$ & $0.63 \pm 0.0004$ & $53.15 \pm 0.1200$ & $1.9 \pm 0.1049$ & $0.04 \pm 0.0020$ \\
4 & $50.40 \pm 0.1016$ & $1.08 \pm 0.0006$ & $53.88 \pm 0.1205$ & $3.3 \pm 0.1141$ & $0.06 \pm 0.0021$ \\
5 & $26.30 \pm 0.0530$ & $0.09 \pm 0.0001$ & $28.79 \pm 0.0837$ & $0.4 \pm 0.1002$ & $0.01 \pm 0.0035$ \\
6 & $26.20 \pm 0.0528$ & $0.36 \pm 0.0002$ & $28.96 \pm 0.0836$ & $1.9 \pm 0.1049$ & $0.07 \pm 0.0036$ \\
7 & $26.50 \pm 0.0534$ & $0.63 \pm 0.0004$ & $29.53 \pm 0.0840$ & $3.0 \pm 0.1118$ & $0.10 \pm 0.0038$ \\
8 & $26.40 \pm 0.0532$ & $1.08 \pm 0.0006$ & $29.88 \pm 0.0839$ & $3.3 \pm 0.1141$ & $0.11 \pm 0.0038$ \\
9 & $9.18 \pm 0.0185$ & $0.09 \pm 0.0001$ & $11.67 \pm 0.0674$ & $0.4 \pm 0.1002$ & $0.03 \pm 0.0086$ \\
10 & $9.44 \pm 0.0190$ & $0.36 \pm 0.0002$ & $12.20 \pm 0.0675$ & $1.1 \pm 0.1017$ & $0.09 \pm 0.0084$ \\
11 & $9.48 \pm 0.0191$ & $0.63 \pm 0.0004$ & $12.51 \pm 0.0676$ & $2.7 \pm 0.1097$ & $0.22 \pm 0.0088$ \\
12 & $9.46 \pm 0.0191$ & $1.08 \pm 0.0006$ & $12.94 \pm 0.0676$ & $2.6 \pm 0.1090$ & $0.20 \pm 0.0085$ \\
13 & $0.94 \pm 0.0019$ & $0.09 \pm 0.0001$ & $3.43 \pm 0.0648$ & $0.1 \pm 0.1000$ & $0.03 \pm 0.0292$ \\
14 & $0.90 \pm 0.0018$ & $0.36 \pm 0.0002$ & $3.66 \pm 0.0648$ & $0.1 \pm 0.1000$ & $0.03 \pm 0.0273$ \\
15 & $0.94 \pm 0.0019$ & $0.63 \pm 0.0004$ & $3.97 \pm 0.0648$ & $0.1 \pm 0.1000$ & $0.03 \pm 0.0252$ \\
16 & $0.98 \pm 0.0020$ & $0.96 \pm 0.0005$ & $4.34 \pm 0.0648$ & $0.1 \pm 0.1000$ & $0.02 \pm 0.0230$ \\
\hline
\end{tabular}

${ }^{a}$ Calculated using a $P_{H}$ of $2.4 \pm 0.0648 \mathrm{~W}$.

\section{Parameter Tuning Analysis}

A color map with a blue scale is used to represent the consumed power, the generated water rate, and the system performance, where darker colors mean higher values. These FoMs are presented in Figures 11-13. According to the presented results, the maximum power consumed by the prototype was $53.88 \mathrm{~W}$ in Test 4 , using the maximum voltage ratings of the devices, as shown in Figure 11. The maximum generated water rate was obtained in Tests 4 and $8(3.3 \mathrm{~mL} / \mathrm{h})$, followed by Tests 7 and $11(3.0 \mathrm{~mL} / \mathrm{h}$ and $2.7 \mathrm{~mL} / \mathrm{h}$, respectively), as shown in Figure 12. Additionally, the highest system performance was $0.22 \mathrm{~mL} / \mathrm{Wh}$ in Test 11, followed by $0.20 \mathrm{~mL} / \mathrm{W}$ in Test 12 .
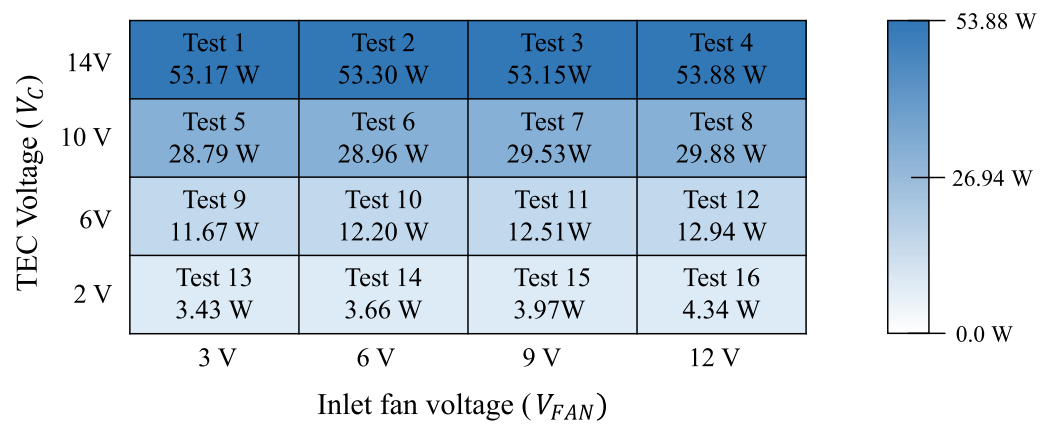

Figure 11. Color map of the consumed power space.

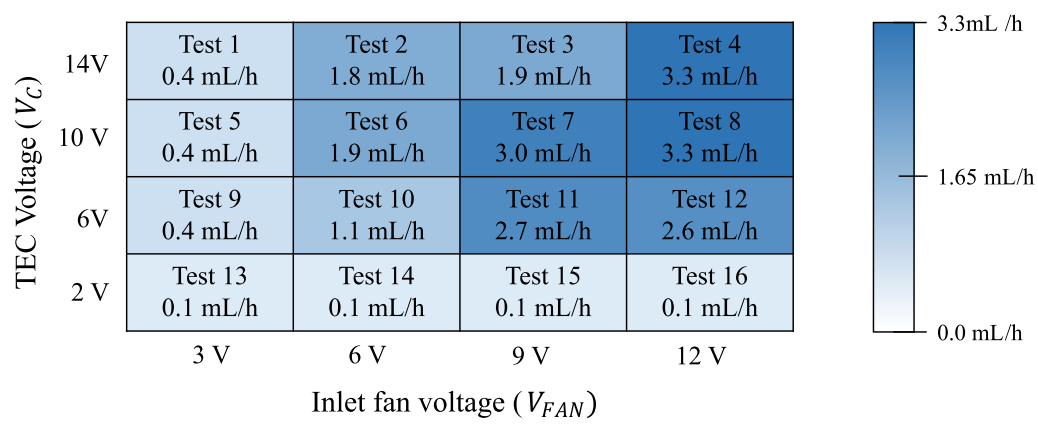

Figure 12. Color map of the generated water space. 


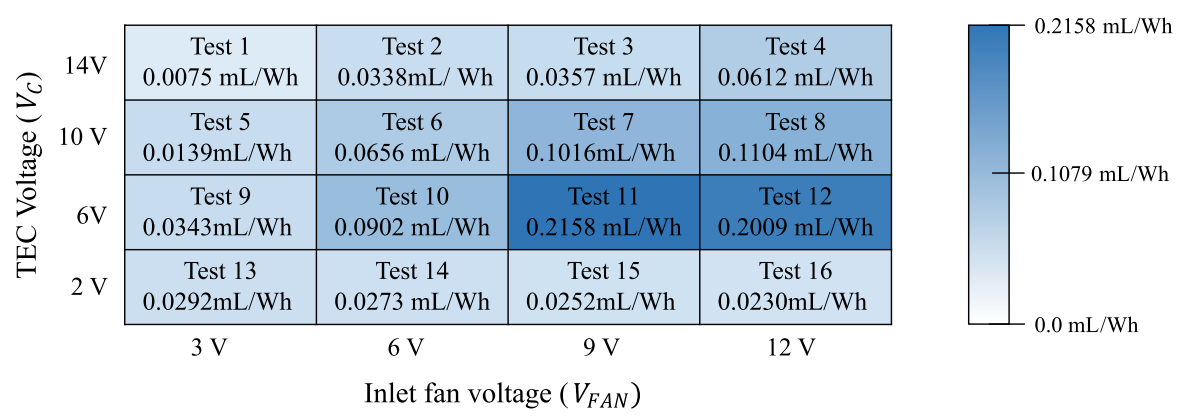

Figure 13. Color map of the system performance space.

According to the mentioned swept test results, we found two optimal operating points of the prototype. The first point maximized the generated water rate at $3.3 \mathrm{~mL} / \mathrm{h}$ using a $V_{C}$ and $V_{F A N}$ of $10 \mathrm{~V}$ and $12 \mathrm{~V}$, respectively. Although this value was obtained in two tests (4 and 8), Test 8 was selected because it had the lowest consumed power. The second operating point maximized the system performance to $0.22 \mathrm{~mL} / \mathrm{Wh}$ with a water generation of approximately $2.7 \mathrm{~mL} / \mathrm{h}$. This optimum operation was achieved using a $V_{C}$ and $V_{F A N}$ of $6 \mathrm{~V}$ and $9 \mathrm{~V}$, respectively.

\section{Comparison of the Proposed PAWG with the SoA}

The results showed a maximum system performance of $0.22 \mathrm{~mL} / \mathrm{Wh}$. In Table 4, the proposed PAWG is compared with the SoA through the devices' FoMs. Furthermore, it summarizes other relevant characteristics of the compared prototypes, such as the size, the volume, the test conditions, the number of TECs, and the consumed power.

The highest $P_{\text {sys }}$ was $0.5 \mathrm{~mL} / \mathrm{Wh}$, which was reported in [14], and the lowest $P_{\text {sys }}$ was $0.04 \mathrm{~mL} / \mathrm{Wh}$, which was reported in [12]. Although our device presented a $P_{\text {sys }}$ below the mean $(0.27 \mathrm{~mL} / \mathrm{Wh})$, it had the lowest $(12.5 \mathrm{~W})$, which is $8.5 \%$ of the mean $(67.9 \mathrm{~W})$. Furthermore, the proposed prototype is portable, simple, and low-cost because of its volume and simple topology with only one TEC module. However, the proposed PAWG design must be improved to increase the PAWG $P_{s y s}$. For instance, the cooling cabin design could be improved.

Table 4. Comparison with other PAWG systems.

\begin{tabular}{|c|c|c|c|c|c|c|c|c|c|}
\hline Ref. & $\begin{array}{c}\text { Publication } \\
\text { Year }\end{array}$ & $\begin{array}{l}T_{a m b} \\
\left({ }^{\circ} \mathrm{C}\right)\end{array}$ & $\begin{array}{l}R H \\
(\%)\end{array}$ & $\begin{array}{c}\text { PAWG Size } \\
\mathbf{L} \times \mathbf{H} \times \mathbf{W}(\mathrm{m})\end{array}$ & $\begin{array}{c}\text { PAWG Volume } \\
\left(\mathrm{m}^{3}\right)\end{array}$ & $\begin{array}{c}\text { TEC } \\
\text { Number }\end{array}$ & $\begin{array}{l}P_{A W G} \\
\text { (W) }\end{array}$ & $\begin{array}{c}w_{g / h} \\
(\mathrm{~mL} / \mathrm{h})\end{array}$ & $\begin{array}{c}P_{\text {sys }} \\
(\mathrm{mL} / \mathrm{Wh})\end{array}$ \\
\hline [12] & 2017 & 30.0 & 63.0 & $0.7 \times 0.40 \times 0.45$ & 0.1260 & 10 & 135.0 & 5 & 0.04 \\
\hline [11] & 2013 & 18.0 & 60.0 & unknown & unknown & 2 & 50.0 & 4 & 0.08 \\
\hline$[9,10]$ & 2017,2020 & 24.3 & 67.8 & $0.46 \times 0.14 \times 0.15$ & 0.0097 & 2 & 52.3 & 11.2 & 0.21 \\
\hline $\begin{array}{l}\text { This work } \\
\text { (Test 11) }\end{array}$ & 2019 & 20.6 & 62.1 & $0.12 \times 0.10 \times 0.27$ & 0.0032 & 1 & 12.5 & 2.7 & 0.22 \\
\hline [15] & 2002 & 27.0 & 82.0 & $0.20 \times 0.18 \times 0.30$ & 0.0108 & 3 & 100.0 & 40.3 & 0.40 \\
\hline [16] & 2016 & 25.3 & 60.0 & $0.35 \times 0.10 \times 0.10$ & 0.0035 & 2 & 65.5 & 27.9 & 0.43 \\
\hline [14] & 2018 & 30.0 & 60.0 & $0.43 \times 0.34 \times 0.17$ & 0.0249 & 4 & 60.0 & 30 & 0.50 \\
\hline
\end{tabular}

\section{Conclusions}

This paper presents an experimental parameter tuning process. The results show the existence of two optimal operation points of the analyzed PAWG under a constant value of relative humidity. One optimum point maximizes the amount of generated water, and the other maximizes the system performance. The resulting FoMs of the developed PAWG prototype are $0.33 \mathrm{~mL} / \mathrm{h}$ of generated water and $0.22 \mathrm{~mL} / \mathrm{Wh}$ for the system performance. Furthermore, these optimum points are not located in the extreme values of the analyzed tuning parameters. Therefore, to guarantee optimum operation under varying humidity conditions, an automatic tuning process could be explored. From the 
comparison of the developed PAWG with the SoA, the system performance is acceptable with a very low power consumption $(12.5 \mathrm{~W})$; therefore, it could be easily powered by an energy harvester device.

Author Contributions: Conceptualization, all authors; methodology, I.C. and C.-I.P.-R.; validation, all authors; analysis, all authors; writing, original draft preparation, all authors; writing, review and editing, all authors; visualization, all authors; supervision, C.-I.P.-R., M.P. and A.F. All authors read and agreed to the published version of the manuscript.

Funding: This research received no external funding.

Institutional Review Board Statement: Not applicable.

Informed Consent Statement: Not applicable.

Data Availability Statement: The data presented in this study are available on request from the corresponding author.

Acknowledgments: The authors would like to thank the Electronics Department and Electronics laboratory of the Pontificia Universidad Javeriana, for providing the required resources to conduct this study. Additionally, the authors would like to thank the Pontificia Universidad Javeriana for financial support in the publication of the results of this study.

Conflicts of Interest: The authors declare no conflict of interest.

\section{Abbreviations}

The following abbreviations are used in this manuscript:

$\begin{array}{ll}\text { AWG } & \text { Atmospheric Water Generator } \\ \text { PAWG } & \text { Portable Atmospheric Water Generator } \\ \text { CPU } & \text { Central Processing Unit } \\ \text { FoM } & \text { Figure of Merit } \\ \text { PWM } & \text { Pulse-Width Modulation } \\ \text { RH } & \text { Relative Humidity } \\ \text { TEC } & \text { Thermoelectric Cooler } \\ \text { SoA } & \text { State-of-the-Art } \\ \text { Std. dev. } & \text { Standard deviation }\end{array}$

\section{References}

1. Tu, R.; Hwang, Y. Reviews of atmospheric water harvesting technologies. Energy 2020, 117630. [CrossRef]

2. Martines, E.; Lira, L. Cálculo de la Temperatura de Punto de Rocío a Diferentes Valores de Presión; Simposio de Metrología: Santiago de Querétaro, Mexico, 2008; Volume 22.

3. Lawrence, M.G. The relationship between relative humidity and the dewpoint temperature in moist air: A simple conversion and applications. Bull. Am. Meteorol. Soc. 2005, 86, 225-234. [CrossRef]

4. Pereira, L.S.; Cordery, I.; Iacovides, I. Coping with Water Scarcity: Addressing the Challenges; Springer: Berlin/Heidelberg, Germany, 2009.

5. Molden, D. Water for Food Water for Life: A Comprehensive Assessment of Water Management in Agriculture; Routledge: London, UK, 2013.

6. Cerro, C. Developing solutions for dealing with water and food scarcity: Atmospheric water generator and urban farm tower. In Proceedings of the 2018 IEEE Advances in Science and Engineering Technology International Conferences (ASET), Abu Dhabi, UAE, 6 February-5 April 2018; pp. 1-6.

7. Pontious, K.; Weidner, B.; Guerin, N.; Dates, A.; Pierrakos, O.; Altaii, K. Design of an atmospheric water generator: Harvesting water out of thin air. In Proceedings of the 2016 IEEE Systems and Information Engineering Design Symposium (SIEDS), Charlottesville, VA, USA, 29 April 2016; pp. 6-11.

8. Sondergeld, A.; Wang, G.; Dutta, A. Modeling the Viability of a Refrigeration-Based Atmospheric Water Generator under the Present-Day Climate. In Proceedings of the 2019 IEEE Global Humanitarian Technology Conference (GHTC), Seattle, WA, USA, 17-20 October 2019; pp. 1-5. [CrossRef]

9. Liu, S.; He, W.; Hu, D.; Lv, S.; Chen, D.; Wu, X.; Xu, F.; Li, S. Experimental analysis of a portable atmospheric water generator by thermoelectric cooling method. Energy Procedia 2017, 142, 1609-1614. [CrossRef]

10. He, W.; Yu, P.; Hu, Z.; Lv, S.; Qin, M.; Yu, C. Experimental Study and Performance Analysis of a Portable Atmospheric Water Generator. Energies 2020, 13, 73. [CrossRef] 
11. Muñoz-García, M.; Moreda, G.; Raga-Arroyo, M.; Marín-González, O. Water harvesting for young trees using Peltier modules powered by photovoltaic solar energy. Comput. Electron. Agric. 2013, 93, 60-67. [CrossRef]

12. Joshi, V.; Joshi, V.; Kothari, H.; Mahajan, M.; Chaudhari, M.; Sant, K. Experimental investigations on a portable fresh water generator using a thermoelectric cooler. Energy Procedia 2017, 109, 161-166. [CrossRef]

13. Zhao, D.; Tan, G. A review of thermoelectric cooling: Materials, modeling and applications. Appl. Therm. Eng. 2014, 66, 15-24. [CrossRef]

14. Shourideh, A.H.; Ajram, W.B.; Al Lami, J.; Haggag, S.; Mansouri, A. A comprehensive study of an atmospheric water generator using Peltier effect. Therm. Sci. Eng. Prog. 2018, 6, 14-26. [CrossRef]

15. Vián, J.; Astrain, D.; Dominguez, M. Numerical modelling and a design of a thermoelectric dehumidifier. Appl. Therm. Eng. 2002, 22, 407-422. [CrossRef]

16. Suryaningsih, S.; Nurhilal, O. Optimal design of an atmospheric water generator (AWG) based on thermo-electric cooler (TEC) for drought in rural area. In AIP Conference Proceedings; AIP Publishing LLC: Melville, NY, USA, 2016; Volume 1712, p. 030009.

17. Casallas, I.; Paéz, C.; Fajardo, A. Recolección de Agua Líquida por Condensación de Humedad Atmosférica Usando el Efecto Peltier; Pontificia Universidad Javeriana: Bogota, Colombia, 2019.

18. DC FANS—50 × 50 × 10 mm. Available online: http://www.wakefieldvette.com/Portals/0/DC $\% 20$ Fans/DC $\% 20 F A N S \% 20$ Wakefield\%20Vette\%20Data\%20Sheet_rev\%20A.pdf (accessed on 28 December 2020).

19. Bench Multimeters, 45 Dual Display Multimeter. FLUKE. Available online: http://www.smart-inc.com.tw/uploads/root/fluke4 5.pdf (accessed on 28 December 2020).

20. Type K Thermocouple. REOTEMP. Available online: https://www.thermocoupleinfo.com/type-k-thermocouple.htm (accessed on 28 December 2020).

21. Calculating Thermocouple Measurement Error in DMM/Switch Temperature Measurement Systems. National Instruments Available online: https:/ / knowledge.ni.com/KnowledgeArticleDetails?id=kA03q000000x0dBCAQ\&l=es-CO (accessed on 28 December 2020).

22. NI USB-621x Specification. National Instruments. Available online: http://www.dept.aoe.vt.edu/ devenpor/aoe3054/manual/ inst3/USB-6211.pdf (accessed on 28 December 2020).

23. Duff, M.; Towey, J. Two Ways to Measure Temperature Using Thermocouples Feature Simplicity, Accuracy, and Flexibility. Analog Dialogue. 2010. Available online: https://www.analog.com/en/analog-dialogue/articles/measuring-temp-usingthermocouples.html (accessed on 28 December 2020).

24. BME280, Combined Humidity and Pressure Sensor. BOSCH. Available online: https://www.bosch-sensortec.com/media/ boschsensortec/downloads/datasheets/bst-bme280-ds002.pdf (accessed on 28 December 2020). 